\title{
PEMANFAATAN MEDIA VIDEO TUTORIAL TERHADAP HASIL PEMBELAJARAN MENGGAMBAR SISWA KELAS VIII SMP NEGERI 1 MARDINDING
}

\author{
Theoria Lamrose $^{1 *}$, Dwi Budiwiwaramulja ${ }^{2 *}$, Azmi $^{3^{*}}$, Muslim $^{4^{*}}$ \\ Program Studi Pendidikan Seni Rupa Jurusan Seni Rupa Fakultas Bahasa dan Seni \\ Universitas Negeri Medan \\ Jl. Willem Iskandar Pasar V Medan Estate, Kec, Percut Sei Tuan, Kab. Deli Serdang, Kode Pos 20371 \\ Sumatera Utara. Indonesia \\ Email: theoria.barus@yahoo.com
}

\begin{abstract}
Abstrak
Penelitian ini bertujuan untuk mengetahui peran penggunaan media video tutorial terhadap meningkatkan hasil gambar ilustrasi siswa kelas VIII SMP Negeri 1 Mardingding tahun 2018. Penelitian ini termasuk pada jenis penelitian eksperimen semu. Sampel yang digunakan dalam penelitian ini terdiri 23 hasil gambar pretest dan 23 hasil gambar posttest, Perlakuan tes dilakukan dengan sampel yang sama, pengambilan sampel dilakukan secara Random Sampling. Hasil penelitian menunjukan bahwa, pemanfaatan media video tutorial pada siswa kelas VIII SMP Negeri 1Mardingding, pretest dengan rata-rata 77,391 dan posttest dengan rata-rata 82,173 dengan demikian dapat di peroleh nilai $t$ yaitu $t_{\text {hitung }}=9,962 \geq t_{\text {tabel }}=2,021$ maka $H a$ di terima dan $H o$ di tolak, sehingga memiliki pengaruh yang signifikan terhadap hasil pembelajaran siswa kelas VIII SMP Negeri 1 Mardingding.
\end{abstract}

Kata Kunci: video tutorial, hasil belajar, ilustrasi.

\begin{abstract}
This study aims to determine the role of using video tutorial media to improve the illustration results of eight grade students of SMP Negeri 1 Mardingding in 2018. This research is included in a quasiexperimental type. The samples that used in this study consisted of 23 images of pretest and 23 results of posttes images, in which the treatment was carried out with the same sample, taking the sample was done in a random way. The results of the study showed that, the use of video tutorial media for eight grade students of SMP Negeri 1 Mardinding, Pretest with an average of 77,391 and posttest with an average of 82,173 , thus can be obtained $t_{\text {value }}=9,962 \geq t_{\text {tabel }}=2,021$, do that Ha is accepted and Ho is rejected, so it has a significant influence on the learning, outcomes of eight grade students of SMP Negeri 1 Mardingding..
\end{abstract}

Keywords: tutorial video, learning outcomes, illustration.

\section{PENDAHULUAN}

Pendidikan saat ini sudah menjadi sebuah kebutuhan hidup manusia, yang dengan pendidikan akan menghasilkan manusia-manusia yang memiliki intelektual tinggi dan bisa memanfaatkan keahliannya untuk kehidupannya. Pendidikan di sekolah adalah kunci awal lahirnya manusia-manusia cerdas yang memiliki potensi diri yang tinggi.

Undang-Undang Pendidikan 2003 menjelaskan tentang ketentuan umum Bab I Pasal I No 1 "Pendidikan adalah usaha sadar dan terencana untuk mewujudkan suasana belajar dan peroses pembelajaran agar peserta didik secara aktif mengembangkan potensi dirinya untuk memiliki kekuatan spiritual keagamaan, pengendalian diri, keperibadian, kecerdasan, akhlak mulia, serta keterampilan yang diperlukan dirinya, masyarakat, bangsa dan negara”. Menghasilkan manusia yang cerdas perlulah kiranya dilakukan upaya-upaya serta kerja keras seorang guru agar yang diharapkan tercapai.Kurikulum 2013 juga menekankan agar guru memiliki perencanaa, pengorganisasian, pengarahan, pengawasan, pembiayaan, dan pelaporan dengan menggunakan atau memanfaatkan fasilitas yang tersedia.Sehingga sesuai dengan Kurikulum sebagai Peroses dan Praktis Kontekstual oleh kementerian pendidikan dan kebudayaan Republik Indonesial (2014: 20-21).Dalam memanfaatkan fasilitas yang tersedia guru mampu meningkatkan hasil belajar siswa. 


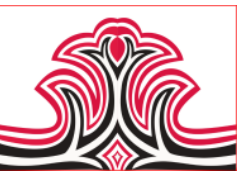

Upaya untuk meningkatkan kualitas proses dan hasil pendidikan di zaman yang penuh dengan penggunaan digital, teknologi pengajaran adalah salah satu upaya yang dapat dilakukan untuk dapat meningkatkan kualitas pengajaran. Teknologi pengajaran juga memberikan alternatif terhadap rancangan program pengajaran dan strategi pelaksanaanya. Teknologi ini juga sangat berguna dalam proses belajar dan mengajar dalam mata pelajaran seni rupa.

Penggunaan teknologi pengajaran yang dilakukan oleh guru di SMP Negeri 1 Mardingding, ternyata belum menggunakan media teknonogi berupa video tutorial pembelajaran.Media yang digunakan masih sebatas buku dan gambar-gambar pendukung yang diberikan oleh guru seni budaya.

Menurut beberapa hasil penelitian bahwa penggunaan media video tutorial lebih berdampak positif pada hasil pembelajaran dibandingkan dengan hanya menggunakan buku atau gambar. Namun demikian masih ada guru belum memanfaatkan teknologi yang difasilitasi oleh sekolah dan ada pula guru belum menggunakan teknologi dalam proses belajar mengajar. Dalam hal ini guru dan fasilitas sekolah sangat berpengaruh meningkatkan kemampuan siswa. Prapenelitan yang dilakukan penulis pada tanggal 2024 Januari 2018 di SMP Negeri 1 Mardinding, melihat bahwa penggunaan media yang mendukung peningkatan belajar siswa kurang baik, dikarenakan guru belum menggunakan teknologi yang sudah difasilitasi oleh sekolah.

Masalah yang ingin diteliti serta sebagai pedoman penulis dalam melakukan penelitian berdasarkan latar belakang masalah, maka identifikasi masalah dalam penelitian ini antara lain :

1. Siswa belum difasilitasi dengan media video dalam proses pembelajaran yang dapat meningkatkan kemampuan menggambar siswa.

2. Guru belum memanfaatkan fasilitas sekolah yang ada dalam materi pembelajaran ilustrasi.

3. Siswa kurang menguasai pengetahuan tentang prinsip komposisi, proporsi, prespekrif dan irama seni rupa dalam menggambar ilustrasi lingkungan sekolah.

Siswa belum mampu mengaplikasikan prinsip komposisi, proporsi, prespekrif dan irama seni rupa dalam menggambar ilustrasi sehingga hasil gambar kurang baik.
Gorga Jurnal Seni Rupa

Volume 08 Nomor 01 Januari-Juni 2019

p-ISSN: 2301-5942 | e-ISSN: 2580-2380

Sesuai identifikasi masalah di atas maka peneliti membatasi masalah pada penelitian ini dengan batasan berikut ini :

1. Penelitian berfokus pada penerapan media video tutorial yang difungsikan untuk membantu meningkatkan keterampilan menerapkan prinsip komposisi, proporsi, prespekrif dan irama seni rupa.

2. Pembelajaran dilakukan pada siswa kelas siswa VIII SMP Negeri 1 Mardingding tahun akademik 2018.

Berdasarkan pembatasan masalah diatas, maka yang menjadi rumusan masalah dalam penelitian ini adalah:

1. Apakah penggunaan media video tutorial dapat meningkatkan hasil menggambar ilustrasi dalam prinsip komposisi, proporsi, prespekrif dan irama seni rupa siswa kelas VIII SMP Negeri 1 Mardingding?

2. Apakah terdapat perbedaan hasil gambar siswa sebelum dan sesudah menggunakan media video tutorial pada siswa kelas VIII SMP Negeri 1 Mardingding ?

Berdasarkan rumusan masalah diatas, maka yang menjadi tujuan penelitian ini adalah:

1. Untuk mengetahui peran penggunaan media video tutorial terhadap meningkatkan hasil menggambar ilustrasi siswa kelas VIII SMP Negeri 1 Mardingding.

2. Untuk melihat perbandingan hasil gambar sebelum dan sesudah penggunaan media video turorial pada siswa kelas VIII SMP Negeri 1 Mardingding.

Setiap penelitian tentu memiliki manfaat baik bagi peneliti maupun pembaca. Adapun manfaat penelitian bagi siswa, guru dan sekolah:

1. Bagi siswa, dapat meningkatkan hasil belajar mengambar ilustrasi, meningkatkan ketrampilan penerapan prinsip komposis, proporsi, prespektif dan irama dalam mengambar ilustrasi siswa kelas VIII SMP Negeri 1 Mardingding.

2. Bagi guru, penelitian ini dapat digunakan untuk meningkatkan hasil belajar, dan mengukur keberhasilannya dalam pelaksanaan kegiatan belajar mengajar, serta memperluas wawasan tentang pengunaan media sederhana guna meningkatkan hasil belajar.

Bagi sekolah, hasil penelitian ini dapat menjadi refrensi sebagi masukan atau evaluasi guna meningkatkan mutu dan kualitas pendidikan di sekolah. 


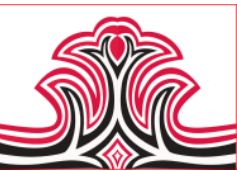

KAJIAN TEORI

\section{Belajar}

Pengertian belajar menurut Asar (2013 : 1) adalah suatu proses yang kompleks yang terjadi pada setiap orang sepanjang hidupnya. Hal ini berarti bahwa berhasil atau gagalnya pencapaian suatu tujuan pendidikan sangat bergantung pada proses belajar yang dialami siswa, baik ketika berada di sekolah maupun di lingkungan masyarakat.

Menurut teori belajar J. Bruner dalam buku Asrar (2013: 9) " belajar tidak untuk mengubah tingkah laku seseorang...”. Sedangakn menurut teori belajar R. Gegne dalam buku yang sama " belajar adalah suatu proses untuk memperoleh motivasi dalam pengetahuan, keterampilan, kebiasaan dan tingkah laku".

Berdasarkan pengertian di atas dapat disimpulkan bahwa belajar merupakan suatu kegiatan yang dilakukan seseorang sehingga terciptanya perubahan tingkah laku dalam dirinya melalui pengajaran baik dari sekolah maupun lingkungan.Perubahan tersebut dapat berupa perkembangan berpikir, keterampilan, maupun sikap dan nilai-nilai di dalam dirinya.

\section{Menggambar Ilustrasi}

Kata ilustrasi berasal dari bahasa latinilustrate yang berarti menjelaskan. Dalam kamus The oxford english, yaitu illustration yang berarti menghiasi dengan gambar-gambar. Dalam kamus yang sama, draw juga secara sederhana dalam bahasa Indonesia yang berarti "gambar". Dapat disimpulkan gambar ilustrasi dapat menjelaskan sesuatu dalam bentuk gambar-gambar.

Veri Ariyanto (2013: 6) mengatakan gambar merupakan wujud pengeksplorasian teknis dan gaya, penggalian gagasan dan kreativitas, bahkan bisa menjadi sebuah ekspresi diri. Menurut Made Wianta dalam bukunya (1999) "The power behind the painting. The whole is constituted by the visible and the invisible. The former can be recorded, while the latter is hidden" yang artinya: kekuatan dibalik lukisan itu adalah keseluruhan dibentuk oleh yang terlihat. Yang pertama dapat direkam, sedangkan yang kedua disembunyikan. Dengan demikian, gambar ilustrasi adalah suatu karya yang merupakan representasi bentuk dan pola melalui ekspresi diri sehingga menghasilkan ide yang bertujuan menjelaskan.

\section{Pengertian dan Jenis Ornamen Sumatera Utara}

Belajar adalah suatu kata yang tidak asing lagi bagi semua orang terutama bagi para pelajar. Kegiatan
Gorga Jurnal Seni Rupa

Volume 08 Nomor 01 Januari-Juni 2019

p-ISSN: 2301-5942 | e-ISSN: 2580-2380

belajar merupakan bagian yang tidak terpisahkan dari semua kegiatan mereka dalam menuntut ilmu di lembaga pendidikan formal.

Menurut John Dewey dalam buku Asar (2013: 19) "Belajar adalah interaksi antara stimulus dengan respon, merupakan hubungan dua arah antara belajar dan lingkungan. Sedangkan pengertian belajar menurut Thorndike (2011: 33) "Belajar adalah asosiasi antara kesan panca indra (sense impresion) dengan impuls untuk bertindak (impuls to action)".Sejalan dengan itu, Iskandar (2012: 102) mengatakan "Belajar merupakan usaha yang dilakukan seseorang melalui interaksi dengan lingkungannya untuk merubah perilakunya”.

Dengan demikian hasil menggambar ilustrasi adalah hasil belajar yang diperoleh siswa sebagai bentuk perubahan tingkah laku setelah melalui proses pembelajaran. Hasil belajar tersebut dinyatakan dalam bentuk visual ilustrasi yang dikerjakan oleh siswa yang di dalamnya memuat beberapa eleman-eleman gambar seperti pola, komposisi, prespektif, dan gelap terang.Untuk dapat meningkatkan kemampuan siswa, media video tutorial sangat berpengaruh dalam peroses belajar mengajar gambar ilustrasi di sekolah.

\section{Media Pembelajaran}

Asrar (2013) dalam bukunya menjelaskan "Kata media berasal dari bahasa latin dan merupakan bentuk jamak dari kata medium yang secara harfiah berarti perantara atau pengantar.Media adalah perantara atau pengantar pesan dari pengirim ke penerima pesan”.

Asosiasi Teknologi dan Komunikasi Pendidikan di Amerika (dalam Asrar, 2013), membatasi media sebagai segala bentuk dan saluran yang digunakan orang untuk menyalurkan pesan atau informasi.

Asosiasi Pendidikan Nasional memiliki pengertian yang berbeda. Media adalah bentuk-bentuk komunikasi baik tercetak maupun audiovisual serta peralatannya.Media hendaknya dapat dimanipulasi, dapat dilihat, didengar dan dibaca.

Berdasarkan beberapa tanggapan $\mathrm{di}$ atas penulis menyimpulkan media adalah segala sesuatu yang dapat digunakan untuk menyalurkan pesan dari pengirim ke penerima sehingga dapat merangsang pikiran, perasaan, perhatian, dan minat serta perhatian siswa sedemikian rupa sehingga proses belajar terjadi dengan baik. Jenis media dalam proses belajar yaitu: Grafis, bahan cetak, gambar diam, media proyeksi 


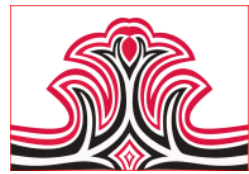

diam, media audio, media gambar hidup, media telivisi, dan media multimedia.

\section{Dasar-Dasar Pembuatan Gambar Ilustrasi}

Ada 3 dasar yang dijadikan pedoman dalam pembuatan gambar ilustrasi menurut Veri (2013) yaitu 1) menguasai teknik, 2) Pesan, 3) Mudah dipahami.

Berikut ini diuraikan secara detail prinsip dasar pembuatan gambar ilustrasi.

1).Penguasaan teknik dalampembuatannyaTampilan gambar sangat ditentukan oleh keahlian pembuatnya. Objek ilustrasi dibuat dengan penguasaan mengambar bentuk yang baik dan menarik.

2).Pesan yang tercantum di dalamnya Gambar ilustrasi yang ditampilkan sesuai atau satu kesatuan dengan isi cerita.

3).Mudah dipahamiSebuah gambar yang menarik memiliki satu kesatuan unsur yangharmonis.

\section{Unsur dalam Pembuatan Gambar Ilustrasi}

Gambar ilustrasi dibangun berdasar dua unsur yaitu 1) unsur visual, 2) unsur non visual dan 3) teknik visualisasi. Unsur visual adalah unsur seni rupa seperti garis, bidang, warna dan sebagainya yang disusun sedemikian rupa dengan suatu prinsip organisasi unsur seni rupa atau sering disebut sebagai komposisi. Unsur non visual adalah berkaitan dengan isi, pesan atau tema dari gambar ilustrasi.

\section{Tahap Menggambar Ilustrasi}

Menurut Veri (2013) untuk menghasilkan sebuah gambar ilustrasi yang baik, ada beberapa tahapan yang harus dilalui oleh seseorang ilustrator yaitu: a) gagasan atau ide, b)sketsa, c) pewarnaan gambar.

\section{Bahan dan Alat Menggambar Ilustrasi}

Pada prinsipnya, tidak ada batasan, baik media atau teknik dalam menggambar maupun melukis. Namun pada umumnya peralatan yang digunakan, antara lain drawing pen, spidol dengan beragam ukuran, pena tulis, kuas, dan pensil

Pewarnaan ilustrasi bisa dibuat hitam-putih atau berwarna.Media pewarnaan bermacam-macam, misalnya pensil warna, cat air, cat poster, krayon, dan lain-lain. Selain mengambar dengan cara manual, teknologi digital sekarang lebih digunakan dalam pembuatan ilustrasi dalam proses pewarnaan.

\section{Prinsip dalam Menggambar Ilustrasi 1). Komposisi}

Gorga Jurnal Seni Rupa

Volume 08 Nomor 01 Januari-Juni 2019

p-ISSN: 2301-5942 | e-ISSN: 2580-2380

Komposisi adalah penempatan dan penyusunan bagian-bagian sebuah gambar untuk membentuk kesatuan dalam sebuah bidang tertentu sehingga enak dipandang (Amir, 1991: 67).Untuk sebuah komposisi tentu harus ada sebuah bidang gambar di mana komposisi itu diatur.

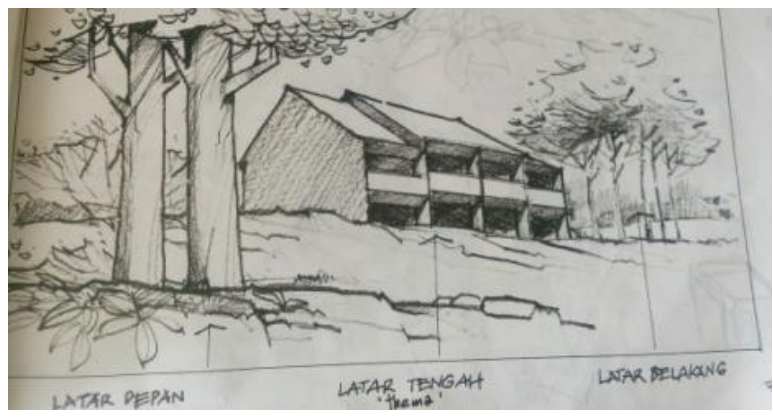

Gambar 1. Komposisi

(Sumber: Thomas C. Wang, -)

\section{2).Bentuk Dasar Benda atau Objek}

Keberhasilan menggambar ilustrasi sangat ditentukan oleh pemahaman tentang bentuk dasar benda yang menjadi objek. Bentuk dasar benda dapat dikelompokkan menjadi tiga, yaitu: Bentuk kubistis, yaitu bentuk benda yang menyerupai kubus.

\section{3).Proporsi}

Sunaryo (2015:21) berpendapat "Proporsi atau kesebandingan adalah hubungan ukuran dalam suatu keseluruhan, yaitu perbandingan panjang pendeknya atau besar-kecilnya bagian satu dengan yang lain, atau antara suatu bagian dengan keseluruhannya.

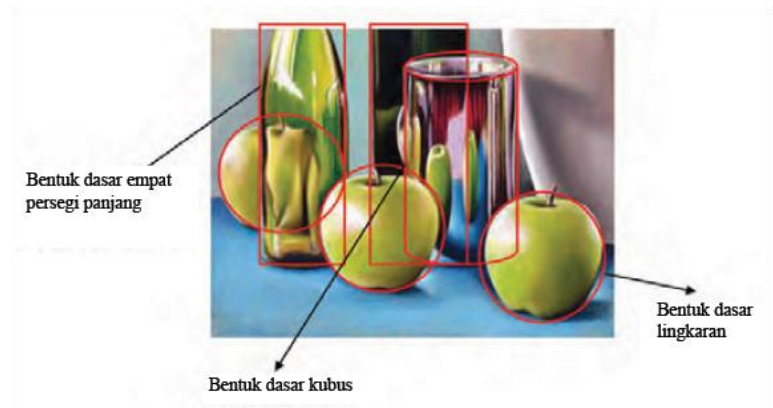

Gambar 2. Proporsi

(Sumber: Nanang Ajmi, -)

\section{4).Prespektif}

Prespektif dapat diartikan sebagai kesan jauh dekat suatu benda dalam gambar dua dimensi, sehingga tampak terkesan tiga dimensi. Dengan menggunakan aturan prespektif dalam menggambar, maka gambar akan terkesan memiliki ruang dan seakan-akan benarbenar tiga dimensi. 

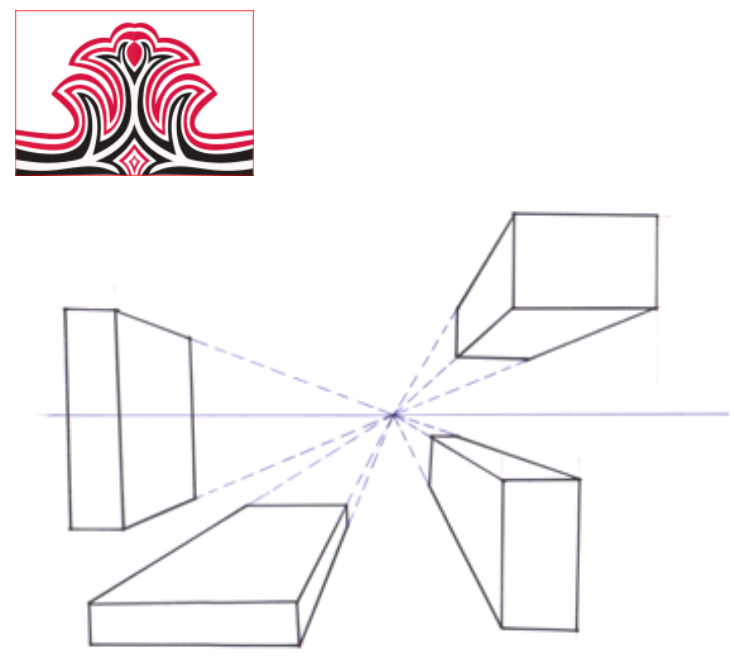

Gambar 3. Prespektif

(Sumber: Bezper Unsoed, -)

\section{5).Irama}

Wucius Wong (1986: 111) menjelaskan “irama adalah kesan bergerak sebuah garis, warna, atau bentuk, baik secara berulang maupun dinamis, sehingga secara keseluruhan tidak monoton. Menurut Dorothea C Malcolm dalam bukunya tentang elements and principles (1985) menuliskan "Complex arrangements have many movements and each is planne todirect us toward a specific point. If the artist has created a rhythmic flow, then our eyes are easly led from one place to another" yang artinya Pengaturan yang kompleks memiliki banyak gerakan dan masing-masing direncanakan untuk mengarahkan kita menuju titik tertentu.

\section{6).Gelap Terang}

Menurut Thomas (1989) "Suatu benda akan terlihat oleh kita apabila terkena sinar. Sebuah benda dapat dilihat karena serapan sinar. Benda itu juga menyerap jenis-jenis warna apapun serta pemantulanpemantulan sinar terhadap benda lain yang sesuai dengan kondisi kekuatan sinar itu dipantulkan”.

\section{7).Sejarah Ilustrasi di Indonesia}

Dalam jurnal ade putri (2016: 78) menjelaskan ilustrasi di Indonesia sudah dikenal sejak lama. Sejarah menunjukkan bahwa sebenarnya nenek moyang kita pada zaman prasejarah sudah mengenal ilustrasi.Hal ini dibuktikan dengan ditemukannya gambar di dalam dinding-dinding gua, salah satunya di Gua Leang-leang, Maros, Sulawesi Selatan yang dibuat pada zaman Palaeolithikum.Gambar tersebut berupa penjiplakan telapak tangan pada dinding gua, didapati juga warna-warna yang dibuat dari tanah liat dicampur lemak binatang.

Seni ilustrasi modren baru berkembang sejak masa panjajahan Belanda. Dalam jurnal seni rupa (Joneta 2012:660-662) menjelakan sejarah perkembangan ilustrasi sejak 1917, bermunculan ilustrator-ilustrator
Gorga Jurnal Seni Rupa

Volume 08 Nomor 01 Januari-Juni 2019

p-ISSN: 2301-5942 | e-ISSN: 2580-2380

Indonesia yang bekerja di Penerbit Balai Pustaka, seperti Ardisoma, Abdul Salam, Kasidi. Pada masa pendudukan jepang, terkenal para ilustrator ternama, seperti Karjono, Norman Kamil, dan Soerono yang bekerja pada majalah Asia Raya.

\section{METODE PENELITIAN}

\section{Lokasi Penelitian}

Penelitian ini berlokasi di SMP Negeri 1 Mardingding. Jalan Medan Kutacane Km 178. Penelitian ini dilakukan selama dua bulan. Menurut Arikunto (2006: 173) "populasi adalah keseluruhan subjek penelitian. Berdasarkan pendapat diatas dapat disimpulkan populasi adalah jumlah dari keseluruhan pada objek penelitian. Adapun yang menjadi populasi dalam penelitian ini yaitu seluruh hasil karya ilustrasi lingkungan sekolah siswa kelas VIII SMP Negeri 1 Mardingding berjumlah 72 siswa. dimana kelas VIII 1 $=23$, kelas VIII $2=24$, kelas VIII $3=23$. Sugiyono (2010: 82). Berdasarkan pada rumus yang dikembangkan Arikunto dan karena adanya beberapa pertimbangan yaitu keterbatasan waktu, tenaga, dan dana, sehingga peneliti mengambil sampel di kelas VIII 1 yang berjumlah 23 hasil karya Gambar Ilustrasi.

\section{Desain Penelitian}

Peneliti memilih menggunakan metode penelitian Quasi Eksperimen (eksperimen semu). Desain penelitian menggunakan rancangan tes, yang dimana dilakukan Pretest sebelum menggunakan video tutorial dan posttest setelah penggunaan video tutorial.

\section{Instrumen Penelitian}

Instrumen penelitian ini terdiri dari:

Pedoman observasi: lembar pengamatan.

Pedoman dokumentasi: kamera, alat tulis.

Tes: pretest, posttest.

\section{Pengumpulan Data}

Instrumen pengumpulan data penelitian ini adalah dokumentasi, tes dan observasi.

\section{Analisis Data}

Dalam penelitian ini proses pengumpulan data dilakukan secara statistic, yaitu dengan rumus statistik uji t (test).

\section{HASIL DAN PEMBAHASAN \\ 1.Hasil Uji Normalitas}

Berdasarkan uji normalitas data dengan teknik Liliefors untuk data pretest dan posttest diperoleh $L o=0,1270<L_{\text {tabel }}=0,190$. Hal ini berarti bahwa data berasal dari populasi berdistribusi normal. 


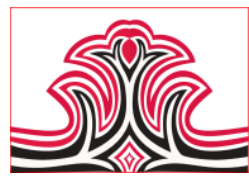

2.Hasil Uji Homogenitas

Hasil pengujian homogenitas menggunakan teknik uji Bartlett Perolehan $x^{2}{ }_{\text {hitung }}=1,45$ dan $x^{2}{ }_{\text {tabel }}=$ 3,84 . sehingga persyaratan homogenitas terpenuhi.

\section{Hasil Uji Hipotesis}

Pada tabel distribusi $\mathrm{t}$ dengan $\mathrm{dk}=40$ dan $\alpha=\mathbf{0 , 0 5}$ didapat $t_{\text {tabel }}=2,021$. Kriteria pengujian yaitu:

Jika hasil $t_{\text {hitung }}<t_{\text {tabel }}$, maka Ho diterima dan tolak $\mathrm{Ha}$

Jika hasil $t_{\text {hitung }} \geq t_{\text {tabel }}$, maka $\mathrm{Ha}$ diterima dan tolak Ho

Ternyata dieroleh hasih $t_{\text {hitung }}=9,962 \geq t_{\text {tabel }}=$ 2,021 maka $H a$ diterima dan $H o$ ditolak.

\section{KESIMPULAN DAN SARAN}

\section{Kesimpulan}

Terdapat pengaruh yang signifikan antara penggunaan strategi pembelajaran pengguanaan media video tutorialdengan tanpa penggunaan media pada materi pembelajaran menggambar ilustrasi dimana $t_{\text {hitung }}=$ $9,962>t_{\text {tabel }}=2,021$.

Terdapat peningkatan hasil menggambar ilustrasi dalam penggunaan media video tutorial siswa kelas VIII SMP Negeri 1 mardingding.

\section{Saran}

Disarankan bagi siswa yang kurang mampu dalam menerapkan perinsip seni rupa dalam menggambar untuk menggunakan video tutorial.

Untuk meningkatkan kemampuan menggambar disarankan berlatih dengan menggunakan video pembelajaran menggambar.

Bagi guru mata pelajaran seni rupa, untuk meningkatkan keterampilan menggambar siswa disarankan menggunakan video pembelajaran menggambar.

Bagi guru agar menggunakan media pembelajran sebagai alternatif strategi pembelajaran dalam meningkatkan kereativitas, minat dan hasil belajar siswa.

Sekolah diharapkan dapat menyediakan alat dan bahan untuk praktikum yang akan dilaksanakan siswa.
Gorga Jurnal Seni Rupa

Volume 08 Nomor 01 Januari-Juni 2019

p-ISSN: 2301-5942 | e-ISSN: 2580-2380

\section{DAFTAR RUJUKAN}

Amir. (1991). Dasar-Dasar Pemotretan Dengan Flem Berwarna. Jakarta : PT. Gramedia Pustaka Utama.

Arikunto, Suharsimi. (2006). Prosedur Penelitian Suatu Pendekatan. Jakarta : Bumi Aksara.

Asrar, Asrul. (2013). Media Pembelajaran.Medan: Perdana Publishing.

Dorothea C. Malcolm. (1985). Design: Elements and Principles. America: United States of America.

Depdikbud. (2014). Kurikulum sebagai Peroses dan Praktis Kontekstual, 20-21.

Joneta, Witabora. (2012). Peran dan Perkembangan Ilustrasi. Jurnal Humaniora Vol 3 (2) 659-667.

Mofit. (2003). Cara Mudah Menggambar. Jakarta : PT Gramedia Pustaka Utama.

Moh, Choirul. (2014). Uji Coba Penggunaan Video Pengajaran Sebagai Upaya Peningkatan Kemampuan Menggambar Karikatur.Jurnal Pendidikan seni rupa, Fakultas Bahasa Dan Seni, Universitas Negeri Surabaya, 2(2) 106115 .

Nana, Ahmad. (2013). Teknologi Pengajaran. Bandung: Sinar Baru Algensindo.

Rookuli Lubis (2013). Penerapan Metode Pembelajaran Explicit Instruction Untuk Meningkatkan Hasil Belajar Menggambar Ilustrasi Di Kelas VIII SMP GKPI Padang Bulan Medan Tahun Pembelajaran 2012/201.Jurnal Pendidikan Seni Rupa, Fakultas Bahasa Dan Seni, Universitas Negeri Medan, 2(2) 67-82.

Sugiyono. (2010). Metode Penelitian Kuantitatif Kualitatif Dan R\&D. Bandung: Alfabeta.

Republik Indonesia. (2003). Undang-Undang Pendidikan Bab 1 No 1 Tahun 2003 Tentang Ketentuan Umum. Jakarta.

Veri. (2013). Cepat dan Mudah Belajar Menggambar Dengan Pensil. Jakarta : Redaksi Kawan Kita.

Wianta, Made. (1999). Made Wianta Universal Balinese Artist. Singapore: Tuck Loong.

Wong, Wucius. (1998). Beberapa Cara Merancang Dwimatra. Bandung : ITB Bandung. 